Article

\title{
Effects of Schiff Base Formation and Aldol Condensation on the Determination of Aldehydes in Rice Wine Using GC-MS
}

\author{
Ji Hye Han ${ }^{\dagger}$, Sang Mi Lee ${ }^{\dagger}$ and Young-Suk Kim * \\ Department of Food Science and Engineering, Ewha Womans University, Seoul 120-750, Korea; \\ wlgo9698@naver.com (J.H.H.); smlee78@ewha.ac.kr (S.M.L.) \\ * Correspondence: yskim10@ewha.ac.kr; Tel.: +82-2-3277-3091; Fax: +82-2-3277-4213 \\ + These authors contributed equally to this work. \\ Academic Editor: Derek J. McPhee \\ Received: 10 March 2017; Accepted: 10 April 2017; Published: 11 April 2017
}

\begin{abstract}
The Schiff base reaction and aldol condensation that occur during sample preparation can lead to the reduction of aldehyde content in the analysis of traditional Korean rice wine, makgeolli. The contents of aldehydes were decreased, whereas those of hydroxy carbonyl compounds were increased by increasing the $\mathrm{pH}$. In the presence of added amino acids, the levels of aldehydes in makgeolli were reduced as the amount of the amino acid alanine increased. Also, the contents of hydroxyl carbonyl compounds were reduced by alanine addition as compared to the control. Therefore, the determination of aldehydes can be affected by $\mathrm{pH}$ and the amount of amino acids, which can vary during fermentation and storage of alcoholic beverages because $\mathrm{pH}$ and amino acids affect Schiff base formation and aldol condensation.
\end{abstract}

Keywords: alcoholic beverage; aldehydes; $\mathrm{pH}$; amino acids; Schiff base formation; aldol condensation

\section{Introduction}

Interest in the analysis of carbonyl compounds in food items and drinks has increased significantly in recent years because some of these compounds are responsible for the unpleasant odors and potential adverse health effects of alcoholic beverages [1-4]. In alcoholic beverages, carbonyl compounds, especially aldehydes, which are formed from by-products of alcoholic fermentation and alcohol oxidation, can affect the quality of beverages because they exhibit unique odor notes, in some instances even at low levels $[1,5]$. Also, these carbonyl compounds can be produced from major macromolecules such as proteins, lipids and carbohydrates from the raw materials used [1]. Therefore, the formation of carbonyls is in part responsible for the quality of alcoholic beverages as well as their safety.

The International Agency on Research for Cancer (IARC) has classified acetaldehyde, which is the major aldehyde and generally comprises more than $90 \%$ of the total aldehydes in wines and distilled alcoholic beverages [6], into group 2B, and acetaldehyde consumed with alcoholic beverages was classified as group 1 with respect to the occurrence of cancer in humans (IARC, 2015).

Aldehydes are present at various levels in alcoholic beverages [7]. The highest aldehyde level normally occurs during fermentation, when the yeast is in the most vigorous phase, although the amount of total aldehydes seems to depend on the types of yeasts and the composition of nutrients used [4]. Large amounts of aldehydes in wine can result from a deficiency of nutrient substances during the fermentation of grapes, which leads to the delayed formation of ethyl alcohol [8]. Diverse reactions such as the oxidation of alcohols, autoxidation of fatty acids, and Strecker degradation of amino acids can also produce aldehydes in alcoholic beverages. 
Carbonyl compounds can be determined by several methods. Enzymatic assay can be used for the determination of acetaldehyde, according to the official methods of the National Research Institute of Brewing (NRIB) and the American Society of Brewing Chemistry (ASBC, 2013). Colorimetric methods for determining acetaldehyde are recommended by the Ministry of Food and Drug Safety (MFDS) and the Food Safety and Standards Authority of India (Fassai). The main advantage of both enzymatic assays and colorimetric methods is that there is no need to use additional instruments, although these methods are less selective and sensitive than instrumental analyses such as gas chromatography (GC) and high performance liquid chromatography (HPLC) [9].

HPLC and GC are most frequently applied to the analysis of carbonyl compounds due to their high resolution and accuracy [1]. Aldehydes and other volatile compounds in alcoholic beverages have been analyzed using gas chromatography-flame ionization detector (GC-FID) combined with direct injection according to the official method of the International Organisation of Vine and Wine (OIV) and the European Union (EU) (EC No. 2870/2000). In general, gas chromatography-mass spectrometry (GC-MS) combined with solid-phase micro-extraction (SPME) has been recommended for the analysis of low molecular mass aldehydes in alcoholic beverages [1]. Because aldehydes are highly volatile and reactive, they usually require derivatization to achieve adequate recovery and sensitivity [10]. SPME has been also applied to determine aldehydes after derivatization in beer [11], wine and spirits [1].

However, determination of carbonyl compounds in alcoholic beverages is limited by problems such as low precision and recovery, mainly because these compounds exhibit high reactivity and volatility [10]. The main reactions related to the loss of aldehydes are due to the formation of Schiff bases and aldol condensation. The formation of Schiff bases usually occurs by the reaction of an aldehyde or ketone with a primary amine under acid or base catalysis or with heat [12], whereas aldol condensation is the reaction of carbonyl compounds, such as nucleophiles, with electrophiles such as aldehydes or ketones to form $\beta$-hydroxyl carbonyl compounds [13]. Although Schiff base formation and aldol condensation can be expected for aldehydes, leading to the loss of those compounds during analysis, there have been no studies to verify their effects on the determination of carbonyl compounds in alcoholic beverages. These reactions are affected by $\mathrm{pH}$ and by other compounds such as amino acids in samples, so investigations to determine aldehydes that take into consideration changes in sample conditions are needed. In this study, the effects of Schiff base formation and aldol condensation on the determination of aldehydes in makgeolli, a traditional rice wine in Korea, were investigated by comparing the amounts and types of aldehydes and hydroxyl carbonyl compounds formed at different $\mathrm{pH}$ values and amino acid levels. Makgeolli was chosen because its contents of amino acids and peptides as well as its $\mathrm{pH}$ can be varied depending on manufacturing processes and storage conditions, which are closely related to its quality.

\section{Results and Discussion}

\subsection{Effect of $\mathrm{pH}$ on the Determination of Aldehydes in Makgeolli}

Makgeolli contains about $7 \%$ ethanol, which is lower than that of either wines or spirits. Also, makgeolli has about $60 \% \sim 70 \%$ of proteins in the dry base which originates from the raw materials [14]. It has been suggested that proteins are readily degraded into low molecular weight peptides and amino acids during fermentation [14]. Aldehydes can also be produced by yeast fermentation or ethanol oxidation. Lee et al. showed that there are 10 aldehydes in makgeolli fermented from Rhizopus japonicas, and that aldehydes make up the main volatile compounds.

The adjustment of $\mathrm{pH}$ values of samples was performed to determine the effect of aldol condensation and Schiff base reaction on the reduction of aldehydes in makgeolli. The contents of aldehydes, except for acetaldehyde, were significantly decreased whereas those of hydroxy carbonyl compounds, except for hydroxyl acetaldehyde, were increased at alkaline $\mathrm{pH}$ (Table 1). These results could be explained by aldol condensation. 
Table 1. Comparison of the contents of aldehydes and hydroxyl carbonyl compounds at different $\mathrm{pH}$ values.

\begin{tabular}{cccc}
\hline \multirow{2}{*}{ Compounds } & \multicolumn{3}{c}{ Relative Peak Area (Mean \pm SD) ${ }^{\mathbf{1}}$} \\
\cline { 2 - 4 } & $\mathbf{p H ~ 4}$ & $\mathbf{p H ~ 7}$ & $\mathbf{p H ~ 1 1}$ \\
\hline acetaldehyde & $2.198 \pm 0.641 \mathrm{a}^{2}$ & $1.919 \pm 0.467 \mathrm{a}$ & $1.802 \pm 0.197 \mathrm{a}$ \\
2-methylpropanal & $1.755 \pm 0.440 \mathrm{a}$ & $1.482 \pm 0.203 \mathrm{a}$ & $0.755 \pm 0.131 \mathrm{~b}$ \\
2-methylbutanal & $1.065 \pm 0.351 \mathrm{a}$ & $1.053 \pm 0.270 \mathrm{a}$ & $0.271 \pm 0.053 \mathrm{~b}$ \\
3-methylbutanal & $3.877 \pm 1.151 \mathrm{a}$ & $3.051 \pm 0.580 \mathrm{a}$ & $1.207 \pm 0.092 \mathrm{~b}$ \\
benzeneacetaldehyde & $0.505 \pm 0.182 \mathrm{a}$ & $0.400 \pm 0.119 \mathrm{a}$ & $0.126 \pm 0.030 \mathrm{~b}$ \\
methional & $0.159 \pm 0.042 \mathrm{a}$ & $0.146 \pm 0.027 \mathrm{a}$ & $\mathrm{ND} \mathrm{b}$ \\
5-methyl-2-furancarboxaldehyde & $0.278 \pm 0.105 \mathrm{a}$ & $\mathrm{ND}^{3} \mathrm{~b}$ & $\mathrm{ND} \mathrm{b}$ \\
3-hydroxy-2-butanone & $0.136 \pm 0.033 \mathrm{c}$ & $0.295 \pm 0.093 \mathrm{~b}$ & $0.614 \pm 0.143 \mathrm{a}$ \\
1-hydroxy-2-propanone & $2.709 \pm 0.817 \mathrm{~b}$ & $6.388 \pm 1.941 \mathrm{~b}$ & $13.212 \pm 4.121 \mathrm{a}$ \\
hydroxy acetaldehyde $_{\text {1-hydroxy-2-butanone }}$ & $0.981 \pm 0.504 \mathrm{~b}$ & $1.937 \pm 0.347 \mathrm{a}$ & $1.605 \pm 0.094 \mathrm{a}$ \\
2-hydroxy-2-cyclopenten-1-one & $0.146 \pm 0.054 \mathrm{~b}$ & $0.280 \pm 0.109 \mathrm{~b}$ & $0.634 \pm 0.265 \mathrm{a}$ \\
\hline 1 Volatile compounds were calculated with the relative peak ratio of their peak areas to that of internal standard \\
(n= 3) \pm standard deviation; ${ }^{2}$ Different letters indicate significant differences $(p<0.1)$ between three different \\
samples according to three different pH values by Duncan's multiple range test; ${ }^{3} \mathrm{ND}=$ not detected.
\end{tabular}

Hydroxyl carbonyl compounds are intermediates of aldol condensation and are more readily produced in basic states. Hydroxyl carbonyl compounds can be converted to unsaturated carbonyl enones, which are stable and irreversible [15]. Most hydroxyl carbonyl compounds are increased at basic $\mathrm{pH}$, whereas hydroxyl acetaldehydes are increased by the neutral state and are decreased under basic conditions. This phenomenon can occur due to the conversion of a hydroxyl acetaldehyde to an unsaturated carbonyl enone, which is relatively stable [15]. However, the reduction of aldehydes also could be explained by Schiff base formation, because it is accelerated by base catalysis.

It has been demonstrated that proline and its derivatives can act as catalysts. The amine group is known to activate the aldol donor molecules by converting them into enamines, while the carboxylic acid provides a hydrogen bond to the acceptor. The enamine functionality is derived by the reaction of a carbonyl compound with a secondary amine [16]. The enamine attacks the carbonyl groups of aldehydes, which leads to aldol condensation [17]. Therefore, a secondary amine can catalyze aldol condensation.

The Schiff base is formed by the reversible reaction between a primary amine and a carbonyl compound (Figure 1) [18]. If both the primary amine and the carbonyl compound are present, a secondary amine is produced by the Schiff base reaction. Then, an enamine is formed by reaction of the secondary amines with other carbonyl compounds. Thus, it can be regarded that a secondary amine from Schiff base formation activates aldol condensation in makgeolli. To investigate the effect of secondary amine formation on aldol condensation, a secondary amine, proline, was added to samples. Table 2 indicates that the contents of hydroxy carbonyl compounds, except for 3-hydroxy-2-butanone, showed a decreasing tendency in accord with the increasing amounts of proline, although some of them were not statistically different among samples. This outcome could result from the activation of aldol condensation by the presence of a secondary amine and by the conversion of hydroxyl carbonyl compounds into unsaturated carbonyl enones, which is an irreversible reaction.

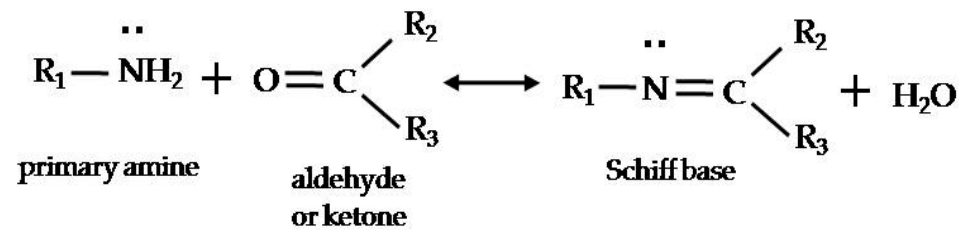

Figure 1. General scheme for formation of Schiff base [18]. 
Table 2. Comparison of the contents of hydroxyl carbonyl compounds by increasing proline.

\begin{tabular}{|c|c|c|c|}
\hline \multirow{2}{*}{ Compounds } & \multicolumn{3}{|c|}{ Relative Peak Area (Mean \pm SD) ${ }^{1}$} \\
\hline & Control (makgeolli) & Control $+50 \mathrm{ppm}$ Proline & Control +100 ppm Proline \\
\hline 3-hydroxy-2-butanone & $0.037 \pm 0.034 \mathrm{~b}^{2}$ & $0.075 \pm 0.017 \mathrm{a}$ & $0.040 \pm 0.010 \mathrm{a}, \mathrm{b}$ \\
\hline 1-hydroxy-2-propanone & $0.116 \pm 0.045 \mathrm{a}$ & $0.088 \pm 0.019 a, b$ & $0.048 \pm 0.014 \mathrm{~b}$ \\
\hline hydroxy acetaldehyde & $0.135 \pm 0.124 \mathrm{a}$ & $0.028 \pm 0.018 \mathrm{a}$ & $0.028 \pm 0.005 a$ \\
\hline 2-hydroxy-2-cyclopenten-1-one & $0.177 \pm 0.153 \mathrm{a}$ & $0.102 \pm 0.053 \mathrm{a}$ & $0.042 \pm 0.001 \mathrm{a}$ \\
\hline
\end{tabular}

The contents of organic acids generally increased during the fermentation period [15]. On the other hand, the maximum content of citric acid, which represents the largest amount of carboxylic acid in makgeolli, was obtained at the seventh day of fermentation, after which its levels decreased [15]. The change in the amounts of organic acids can vary based on variations in $\mathrm{pH}$ during the fermentation process in the preparation of makgeolli, which can ultimately affect the determination of aldehydes.

\subsection{Effects of Amino Acids on the Determination of Aldehydes in Makgeolli}

It is known that free amino acids and peptides are produced from proteins, which are the major raw material in rice, during fermentation of makgeolli [19]. It was reported that makgeolli contains free amino acids that contribute to the sweet, savory, sour, and bitter tastes [20]. Kang et al. reported that commercial makgeolli is composed of $0.2 \% \sim 1.27 \%$ of reducing sugars, $0.47 \% \sim 0.95 \%$ of amino acids, and $0.28 \% \sim 0.57 \%$ of total acids. Alanine, phenylalanine, tyrosine, leucine, glutamic acid, and proline were identified as the major amino acids in makgeolli [15].

Therefore, the effects of amino acids with amine groups on the determination of aldehydes were studied in a subsequent experiment, investigated separately from the $\mathrm{pH}$ effect. In order to investigate the effect of Schiff base formation and the quantitative effect of amino acids, aliquots of $50 \mathrm{mg} / \mathrm{L}$ and $100 \mathrm{mg} / \mathrm{L}$ of alanine were added to samples of makgeolli. Alanine has been identified as a major amino acid in makgeolli and its levels increased in accordance with different parts of the fermentation [11]. The contents of all aldehydes were reduced as the amount of added alanine increased (Table 3). In particular, the contents of acetaldehyde, 2-methylpropanal, 2-methylbutanal, and 3-methylbutanal were significantly decreased as the addition of alanine increased. However, 5-methyl-2-furancarboxaldehyde, 2-methylbutanal, 2-methylpropanal, and benzeneacetaldehyde were slightly decreased, as compared to the controls without the addition of alanine. The contents of some aldehydes were significantly changed by the addition of amino acids, and were also highly affected by the level of alanine. Therefore, amino acids present at different levels during the fermentation of makgeolli [15] can lead to variations in the contents of aldehydes.

Table 3. Comparison of the contents of aldehydes by adding alanine.

\begin{tabular}{cccc}
\hline \multirow{2}{*}{ Compounds } & \multicolumn{3}{c}{ Relative Peak Area (Mean \pm SD) ${ }^{\mathbf{1}}$} \\
\cline { 2 - 4 } & Control (makgeolli) & Control +50 ppm Alanine & Control +100 ppm Alanine \\
\hline acetaldehyde & $2.365 \pm 0.239 \mathrm{a}^{2}$ & $1.726 \pm 0.343 \mathrm{~b}$ & $1.335 \pm 0.147 \mathrm{~b}$ \\
2-methylpropanal & $2.111 \pm 0.175 \mathrm{a}$ & $1.766 \pm 0.505 \mathrm{a}$ & $1.186 \pm 0.097 \mathrm{~b}$ \\
2-methylbutanal & $1.427 \pm 0.218 \mathrm{a}$ & $1.021 \pm 0.419 \mathrm{a}, \mathrm{b}$ & $0.604 \pm 0.204 \mathrm{~b}$ \\
3-methylbutanal & $3.599 \pm 0.406 \mathrm{a}$ & $3.519 \pm 0.773 \mathrm{a}$ & $2.403 \pm 0.140 \mathrm{~b}$ \\
benzeneacetaldehyde & $0.599 \pm 0.135 \mathrm{a}$ & $0.444 \pm 0.111 \mathrm{a}, \mathrm{b}$ & $0.407 \pm 0.095 \mathrm{~b}$ \\
methional & $0.175 \pm 0.025 \mathrm{a}$ & $0.169 \pm 0.053 \mathrm{a}$ & $0.128 \pm 0.026 \mathrm{a}$ \\
5-methyl-2-furancarboxaldehyde & $0.289 \pm 0.102 \mathrm{a}$ & $0.262 \pm 0.188 \mathrm{a}$ & $0.011 \mathrm{a}$ \\
\hline
\end{tabular}

${ }^{1}$ Volatile compounds were calculated with the relative peak ratio of their peak areas to that of internal standard $(n=3) \pm$ standard deviation; ${ }^{2}$ Different letters indicate significant differences $(p<0.1)$ between three different samples according to three different alanine contents by Duncan's multiple range test. 


\section{Materials and Methods}

\subsection{Materials}

Ethanol (>99.9\%) was purchased from Sigma-Aldrich (Sigma-Aldrich, St. Louis, MO, USA) for standards preparation. 4-Methyl-1-pentanol, an internal standard (ISTD) compound, was also obtained from Sigma-Aldrich. DL-alanine and DL-proline were purchased from Sigma-Aldrich and Oasis MAX cartridge $6 \mathrm{cc}$ with stationary phase was purchased from Waters (Waters, Milford, MA, USA).

\subsection{Sample Preparation}

Commercial rice wine (makgeolli) samples were purchased from a local market in Seoul, Republic of Korea. All the samples used were manufactured from the same lot on the same day. All the samples were mixed thoroughly, divided into about $250 \mathrm{~mL}$, and stored at $-70{ }^{\circ} \mathrm{C}$. Then, they were thawed at $1{ }^{\circ} \mathrm{C}$ overnight before conducting the experiments.

\subsection{1. $\mathrm{pH}$}

$4.9 \mathrm{~mL}$ of makgeolli was transferred into a 50-mL falcon tube (Becton Dickinson, Cowley, Oxford, UK). $100 \mu \mathrm{L}$ of 4-methyl-1-pentanol, an internal standard (50 mg/L in ethanol), was added into the sample before the sample was adjusted to neutral or basic condition using $1 \mathrm{M}$ sodium hydroxide $(\mathrm{NaOH})$. The sample was mixed using a vortexer and centrifuged for $10 \mathrm{~min}$ at $4{ }^{\circ} \mathrm{C}$ and $3500 \mathrm{rpm}$. Then supernatant was transferred to a test tube and vortexed. Finally, $1 \mathrm{~mL}$ of supernatant was placed in a 2-mL amber vial.

\subsubsection{Addition of Amino Acid}

$4.4 \mathrm{~mL}$ of makgeolli was transferred into a 50-mL falcon tube. $100 \mu \mathrm{L}$ of 4 -methyl-1-pentanol, an internal standard (50 mg/L in ethanol), and $0.5 \mathrm{~mL}$ of alanine (50 mg/L or $100 \mathrm{mg} / \mathrm{L}$ in water) were added into the sample. The sample was mixed using vortexer and centrifuged for $10 \mathrm{~min}$ at $4{ }^{\circ} \mathrm{C}$ and $3500 \mathrm{rpm}$. Then supernatant was transferred to a test tube and vortexed. Finally, $1 \mathrm{~mL}$ of supernatant was placed in a $2-\mathrm{mL}$ amber vial.

\subsubsection{Addition of Secondary Amine}

$4.7 \mathrm{~mL}$ of makgeolli was transferred into a 50-mL falcon tube. $100 \mu \mathrm{L}$ of 4-methyl-1-pentanol, an internal standard $(100 \mathrm{mg} / \mathrm{L}$ in ethanol), and $0.1 \mathrm{~mL}$ of proline $(50 \mathrm{mg} / \mathrm{L}$ and $100 \mathrm{mg} / \mathrm{L}$ in water) were added into the sample. The sample was mixed using a vortexer and centrifuged for $10 \mathrm{~min}$ at $4{ }^{\circ} \mathrm{C}$, and $3500 \mathrm{rpm}$. Then supernatant was transferred to a test tube and vortexed. Finally, $1 \mathrm{~mL}$ of supernatant was placed in a $2-\mathrm{mL}$ amber vial.

\subsection{Gas Chromatography-Mass Spectrometry (GC-MS) Analysis}

GC-MS analysis was performed using a HP 7890B gas chromatograph (Agilent Technologies, Santa Clara, CA, USA) coupled with a 5977A mass selective detector (MSD) (Agilent Technologies) and a multi-purpose sampler MPS 2 (Gerstel, Mülheim an der Ruhr, Germany). HP-innowax fused silica capillary column $(30 \mathrm{~m}$ length $\times 0.25 \mathrm{~mm}$ internal diameter $\times 0.25 \mu \mathrm{m}$ film thickness; Agilent Technologies) was used with helium, a carrier gas, at a constant flow rate of $1 \mathrm{~mL} / \mathrm{min}$. Injection volume was $1.0 \mu \mathrm{L}$ with split mode (20:1). The oven temperature program started at $40{ }^{\circ} \mathrm{C}$ initially and was held for $3 \mathrm{~min}$, then was raised to $200{ }^{\circ} \mathrm{C}$ at $5^{\circ} \mathrm{C} / \mathrm{min}$ and held at $200{ }^{\circ} \mathrm{C}$ for $3 \mathrm{~min}$. Post run was held at $180^{\circ} \mathrm{C}$ for $2 \mathrm{~min}$. Inlet, detector transfer line and mass source temperatures were 250, 280, $230{ }^{\circ} \mathrm{C}$, respectively. MS was operated in the electron impact (EI) ion source mode at $70 \mathrm{eV}$ with a scan range of 25 350 a.m.u. Ethanol (>99.9\%) was purchased from Sigma-Aldrich (Sigma-Aldrich, St. Louis, MO, USA) for standard preparation. 4-Methyl-1-pentanol, an internal standard (ISTD) compound, was also obtained from Sigma-Aldrich. DL-alanine and DL-proline were purchased from Sigma-Aldrich 
and Oasis MAX cartridge $6 \mathrm{cc}$ with stationary phase was purchased from Waters (Waters, Milford, MA, USA).

\subsection{Statistical Analyses}

Analysis of variance (ANOVA) was performed with a general linear model procedure in SPSS (version 12.0, Chicago, IL, USA) to evaluate significant differences of compounds in samples. Post-hoc analysis was determined using Duncan's multiple comparison test $(p<0.1)$.

\section{Conclusions}

The determination of aldehydes is affected by Schiff base formation and by aldol condensation, reactions which are sensitive to $\mathrm{pH}$ and the presence of amino acids. Therefore, during the determination of aldehydes, the conditions of the samples should be taken into account because $\mathrm{pH}$ and the amounts of amino acids can vary during fermentation and storage of alcoholic beverages or foods and can affect the results of the aldehyde measurements.

Acknowledgments: This study was supported by a grant (15162MFDS004) from the Ministry of Food and Drug Safety in 2015, the Strategic Initiative for Microbiomes in Agriculture and Food, Ministry of Agriculture, Food and Rural Affairs, Republic of Korea (as part of the (multi-ministerial) Genome Technology to Business Translation Program) (No. 916005-2), and the BK21 Plus program funded by the National Research Foundation of Korea (NRF) (No. 22A20130012233).

Author Contributions: Y.-S.K. and J.H.H. designed and performed the experiments; J.H.H., S.M.L. and Y.-S.K. analyzed the data, J.H.H., S.M.L. and Y.-S.K. wrote the paper.

Conflicts of Interest: The authors declare no conflict of interest.

\section{References}

1. Wardencki, W.; Sowinski, P.; Curylo, J. Evaluation of headspace solid-phase microextraction for the analysis of volatile carbonyl compounds in spirits and alcoholic beverages. J. Chromatogr. A 2003, 984, 89-96. [CrossRef]

2. Lago, L.O.; Nicolli, K.P.; Marques, A.B.; Zini, C.A.; Welke, J.E. Influence of ripening and maceration of the grapes on levels of furan and carbonyl compounds in wine-Simultaneous quantitative determination and assessment of the exposure risk to these compounds. Food Chem. 2017, 230, 594-603. [CrossRef]

3. Flamini, R.; Luca, D.G.; Stefano, D.R. Changes in carbonyl compounds in Chardonnay and Cabernet Sauvignon wines as a consequence of malolactic fermentation. J. Grapevine Res. 2002, 41, 107-112.

4. Kang, H.R.; Hwang, H.J.; Lee, J.E.; Kim, H.R. Quantitative analysis of volatile flavor components in Korean alcoholic beverage and Japanese sake using SPME-GC/MS. Food Sci. Biotechnol. 2016, 25, 979-985. [CrossRef]

5. Plutowska, B.; Wardencki, W. Application of gas chromatography-olfactometry (GC-O) in analysis and quality assessment of alcoholic beverages-A review. Food Chem. 2008, 107, 449-463. [CrossRef]

6. Nykänen, L. Formation and occurrence of flavor compounds in wine and distilled alcoholic beverages. Am. J. Enol. Vitic. 1996, 37, 84-96.

7. Radler, F. Bedeutung and möglichkeiten der verwendung von reinkulturen von hefen bei der weinbereitung. Weinb. Keller 1973, 20, 339-350.

8. Wucherpfennig, K.; Semmler, G. Uber den $\mathrm{SO}_{2}$-bedarf der weine aus den verschiedenen weinbaugebieten der welt undessen abhängigkeit von der bildung von acetaldehyde im verlauf der gärung. Dtsch. Weinbau 1973, 28, 851-855.

9. Sowiński, P.; Wardencki, W.; Partyka, M. Development and evaluation of headspace gas chromatography method for the analysis of carbonyl compounds in spirits and vodkas. Anal. Chim. Acta 2005, 539, 17-22. [CrossRef]

10. Wang, Q.; Reilly, J.O.; Pawliszyn, J. Determination of low-molecular mass aldehydes by automated headspace solid-phase microextraction with in-fibre derivatisation. J. Chromatogr. A 2005, 1071, 147-154. [CrossRef] [PubMed]

11. Versely, P.; Lusk, L.; Basarova, G.; Seabrooks, J.; Ryder, D. Analysis of aldehydes in beer using solid-phase microextraction with on-fiber derivatization and gas chromatography/mass spectrometry. J. Agric. Food Chem. 2003, 51, 6941-6944. [CrossRef] [PubMed] 
12. Xavier, A.; Srividhya, N. Synthesis and study of Schiff base ligands. IOSR-J. Appl. Chem. 2014, 7, 6-15. [CrossRef]

13. Clayton, H. The aldol reaction: Acid and general base catalysis. Ref. Modul. Chem. Mol. Sci. Chem. Eng. 1991, 133-179.

14. Rhee, S.J.; Lee, C.Y.; Kim, M.R.; Lee, C.H. Potential antioxidant peptides in rice wine. J. Microbiol. Biotechnol. 2004, 14, 715-721.

15. Kim, H.R.; Kim, J.H.; Ahn, B.H.; Bai, D.H. Metabolite profiling during fermentation of makgeolli by the wild yeast strain saccharomyces cerevisiae Y98-5. Mycobiology 2014, 42, 353-360. [CrossRef] [PubMed]

16. Smith, M.B.; March, J. Advanced Organic Chemistry: Reaction, Mechanisms, and Structure, 6th ed.; Wiley: New York, NY, USA, 1992.

17. Zhong, G.; Lerner, R.A.; Barbas, C.F. Broadening the aldolase catalytic antibody repertoire by combining reactive immunization and transition state theory: New enantio- and diastereoselectivities. Angew. Chem. Int. Ed. 1999, 38, 3738-3741. [CrossRef]

18. Abu-Dief, A.M.; Mohamed, I.M.A. A review on versatile applications of transition metal complexes incorporating Schiff bases. Beni-Suef Univ. J. Basic Appl. Sci. 2015, 4, 119-133. [CrossRef]

19. Park, J.H.; Yeo, S.H.; Jeong, S.T.; Choi, H.S.; Jeon, J.A.; Choi, J.H. Characteristics of byeok-hyang-ju made by various processing methods originated from ancient documents. Korean J. Food Preserv. 2010, 17, 826-834.

20. Shon, S.K.; Rho, Y.H.; Kim, H.J.; Bae, S.M. Takju brewing of uncooked rice starch using Rhizopus koji. Korean J. Appl. Microbiol. Biotechnol. 1990, 18, 500-510.

Sample Availability: Not available.

(C) 2017 by the authors. Licensee MDPI, Basel, Switzerland. This article is an open access article distributed under the terms and conditions of the Creative Commons Attribution (CC BY) license (http://creativecommons.org/licenses/by/4.0/). 